\title{
Value Unlocked: Strategies on Connection between Green Open Space and Healthy Activity in Conghua, Guangzhou
}

\author{
Weikai YU, Guangzhou Urban Planning \& Design Survey Research Institute, China \\ Kejian YU, Guangzhou Urban Planning \& Design Survey Research Institute, China
}

\begin{abstract}
The COVID-19 epidemic has affected people's life activities, which makes the pursuit of health an important starting point for life behavior choices. Guangzhou Conghua is located in the northern part of the Guangdong-Hong Kong-Macao Greater Bay Area in China. This is an urban community area with diverse ecological elements and high-quality ecological environment.

This article analyzes the three characteristics of Conghua's green open space. (environmental quality, scale and distribution) After the COVID-19 epidemic, Conghua's green open space activities have shown new characteristics. First, daily leisure activities prefer community parks with high convenience for sports activities, and weekend leisure activities prefer urban parks with high traffic accessibility and well-open space. Compared with the suburban ecological parks, the third is that vacation activities prefer the outer suburbs ecological parks with good environmental quality. Combining the above-mentioned preference relationship between green open space and living activities, this article proposes that after the COVID-19 epidemic, planning measures can be used to realize the link between green open space and healthy lifestyle, unlock the diversified value of green open space and create a distinctive healthy life model.
\end{abstract}

\section{Keywords}

Conghua, Green open space, Healthy activity, Strategies

\section{Preface}

Natalie Robert, the technical specialist at the Department of Public Health, Environmental and Social Determinants in the WHO, proposed in the article "Green Space: An Invaluable Resource for Delivering Sustainable Urban Health" that "Parks, green spaces and waterways are essential for urban health." solution". At present, global scholars' research on green open space and healthy life mainly focuses on the fields of health, medicine, and the environment, such as the relationship between physical health threats caused by respiratory diseases and the supply of green open space, as well as mental health and social health, etc. This field of studying the nexus between green open space and activities for public health has gradually become a heated topic ${ }^{[1-20]}$. Especially since the outbreak of the Covid pandemic, the pursuit of health has become an important starting point for people's behavioral changes. For now, China's urban development has entered a new era, where ecology and safety are important values in urban development. And green open space is an important support for this.

Guangzhou Conghua is located in the northern part of the Guangdong-Hong Kong-Macao Greater Bay Area in China. This is an urban community area with diverse ecological elements and high-quality ecological 
environment. Mountains, rivers, forests, fields, lakes and other ecological elements are abundant in this area and its comprehensive air quality index ranks first in all districts in Guangzhou. After the COVID-19 epidemic, the green open space of Conghua has seen higher activity flow and activity intensity. Green open space has achieved a significant link with people's healthy life and it has played a more positive value in promoting health. This article takes the Conghua District of Guangzhou City as an example to analyze the relationship between people's daily activity (its frequency, intensity, and type) and green open space, then proposes linking strategies for green open space to promote healthy activities in the future.

\section{Characteristic Analysis of Green Open Space in Conghua District}

Conghua District is located in the north of Guangzhou City, with an administrative area of 1984 square kilometers (Data source : People' s Government of Conghua District, Guangzhou City). The overall topography is high in the northeast and the low in the southwest. Conghua District has always been known as the "Pearl on the Tropic of Cancer" and "Guangzhou's Back Yard". The green open space of Conghua District mainly consists of the surrounding ecological mountain, forest and the suburban park areas. The forest coverage rate in Conghua is more than $69 \%$, ranking first in Guangzhou. Overall, the ecological resources in Conghua are of extremely high quality.

\subsection{Environmental Quality Characteristics of Green Open Space}

Conghua's index of ecological environment ranks first in Guangzhou. According to the environmental quality statistics report data, ecological environment index of Conghua District was 86.7 in 2019, which was far higher than other districts of Guangzhou. Conghua is also ahead of other cities in the Greater Bay Area, such as Shenzhen, Zhuhai and Foshan.

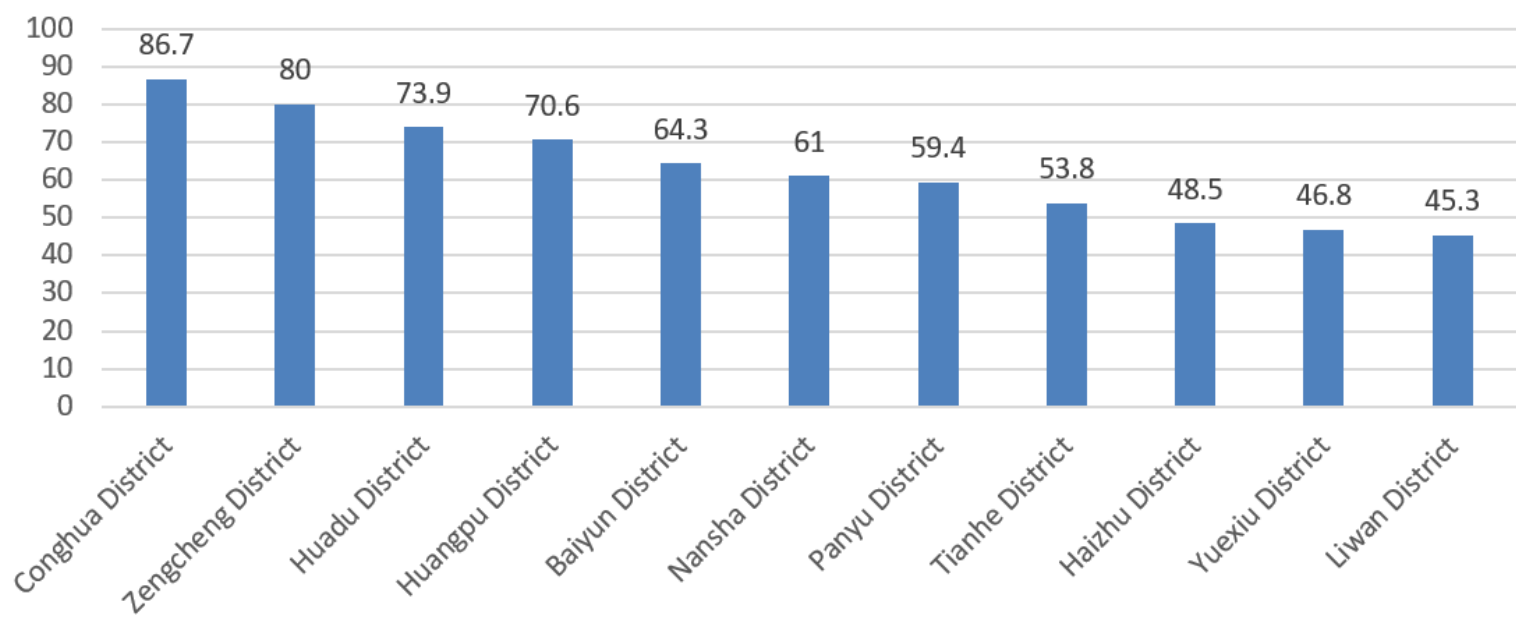

Figure 1. Ecological environmental index of each district in Guangzhou in 2019 (The higher,the better) . Source:Environmental quality statistics report data.

Air quality in Conghua is the best among all districts in Guangzhou. According to the environmental quality statistics report data, the comprehensive index of air quality in Conghua district in January 2020 was 2.61. The annual average concentration of the main pollutants in the air (sulfur dioxide, nitrogen dioxide, inhalable particulate matter, fine particulate matter) has reached the second level. Compared with other areas in Guangzhou, the air quality is in a leading position. 


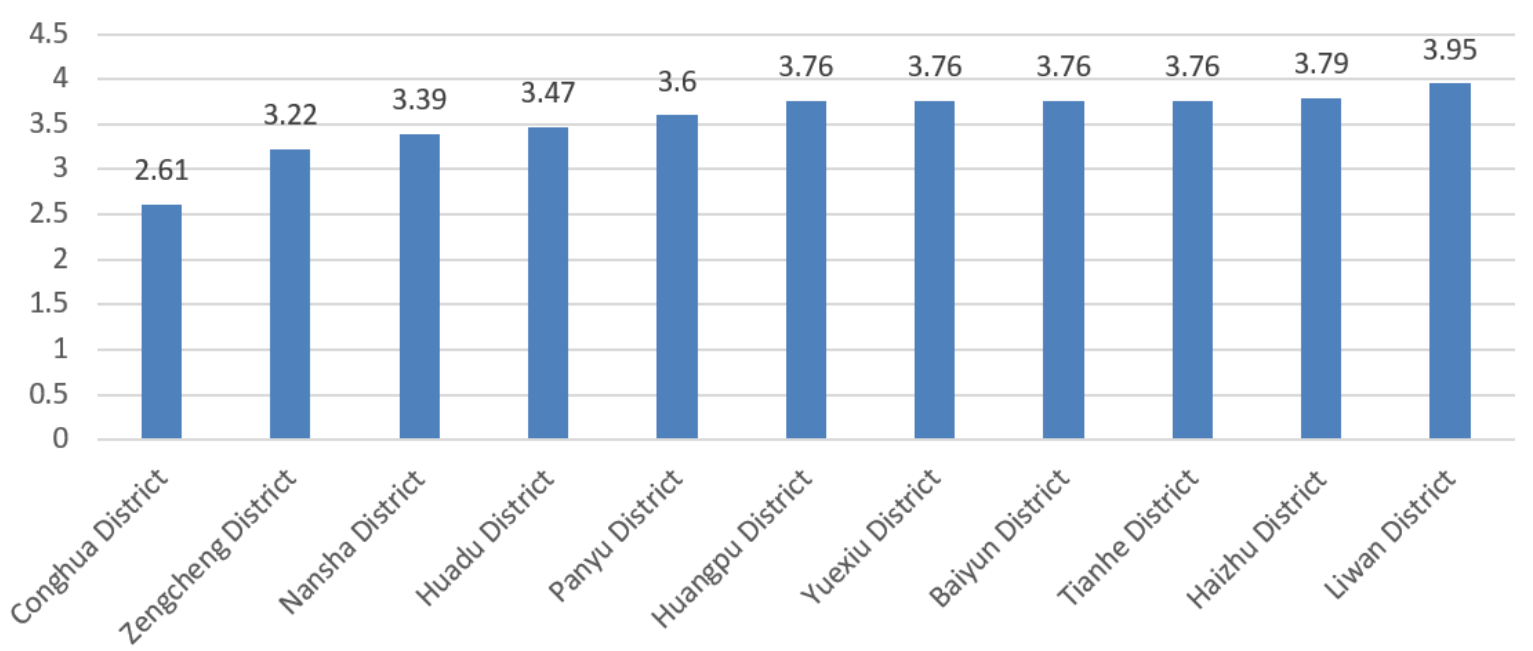

Figure 2. Comprehensive index of air quality of each district in Guangzhou in January 2020 (The lower, the better). Source:Environmental quality statistics report data.

Drinking water supply in Conghua performs excellently. According to the environmental quality statistics report data, the water quality compliance rate of the centralized drinking water source in Conghua district was $100 \%$ in 2020 , which meets the national surface water quality requirements of centralized domestic drinking water. The water quality of the upstream maintained excellent throughout the whole year, and the water quality at all sections reached either Class I or II.

The overall evaluation of the acoustic environment in Conghua is at a good level. According to the latest data released by Conghua District, from January to July 2021, the average daytime equivalent sound level of road traffic noise in Conghua District was 65.0 decibels, and the average daytime equivalent sound level of regional environmental noise was 53.0 decibels. Both of these are classified into the first level and the second level (corresponding evaluation is good and good).

\subsection{Scale Characteristics of green open space}

This article has divided the green open space in Conghua into three types: type less than 2 hectares, type from 2 to 25 hectares, and type greater than 25 hectares. Among the 98 green areas included in the Guangzhou Park List, The number of green open space areas that are less than 2 hectares are the most, with a total number of 48 , accounting for $49 \%$. There are 24 spots in the green open space of $2-25$ hectares, accounting for $24.5 \%$. There are 26 green open space areas that are over 25 hectares, accounting for $26.5 \%$ of the total number. Combining with the area analysis of various green open spaces, we found that although the number of green open spaces with 25 hectares or more do not account for a high proportion, their area accounts for $99.5 \%$ of the total green area in the whole district. 


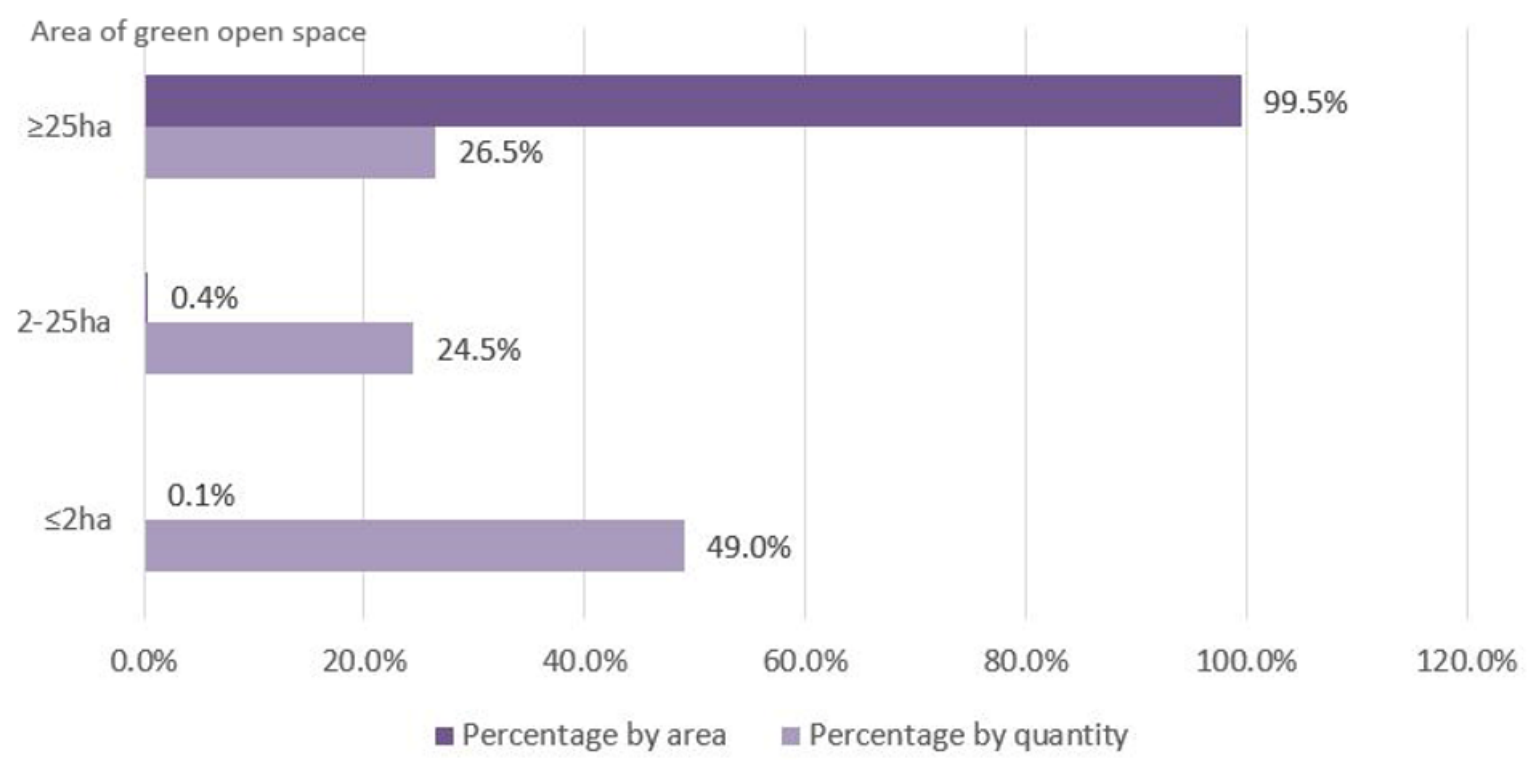

Figure 3 Scale characteristics of green open space on Conghua. Source: The relevant data of Guangzhou green system and authors' survey.

\subsection{Distribution Characteristics of Green Open Space}

The green open space over 25 hectares in Conghua District is mainly composed of nature reserves, forest parks, and national parks, and they're concentrated in the northern part of Conghua District (Lvtian Town, Liangkou Town and Wenquan Town). The green space ranging from 2 to 25 hectares mainly locates at the ecological parks in the suburbs, which are concentrated in the central urban areas (Jiekou Town, Chengjiao Town and Jiangpu Town). The green open space less than 2 hectares is mainly composed of street green space and pocket parks, scattered in the concentrated urban construction area. The three types of green open spaces are connected through the water corridors composed of Liuxi River, Pajiang River, Longtan River, Xiaohai River, Yuxi River, Anshan River, Lvtian River, Lianma River, and Yadong River. 


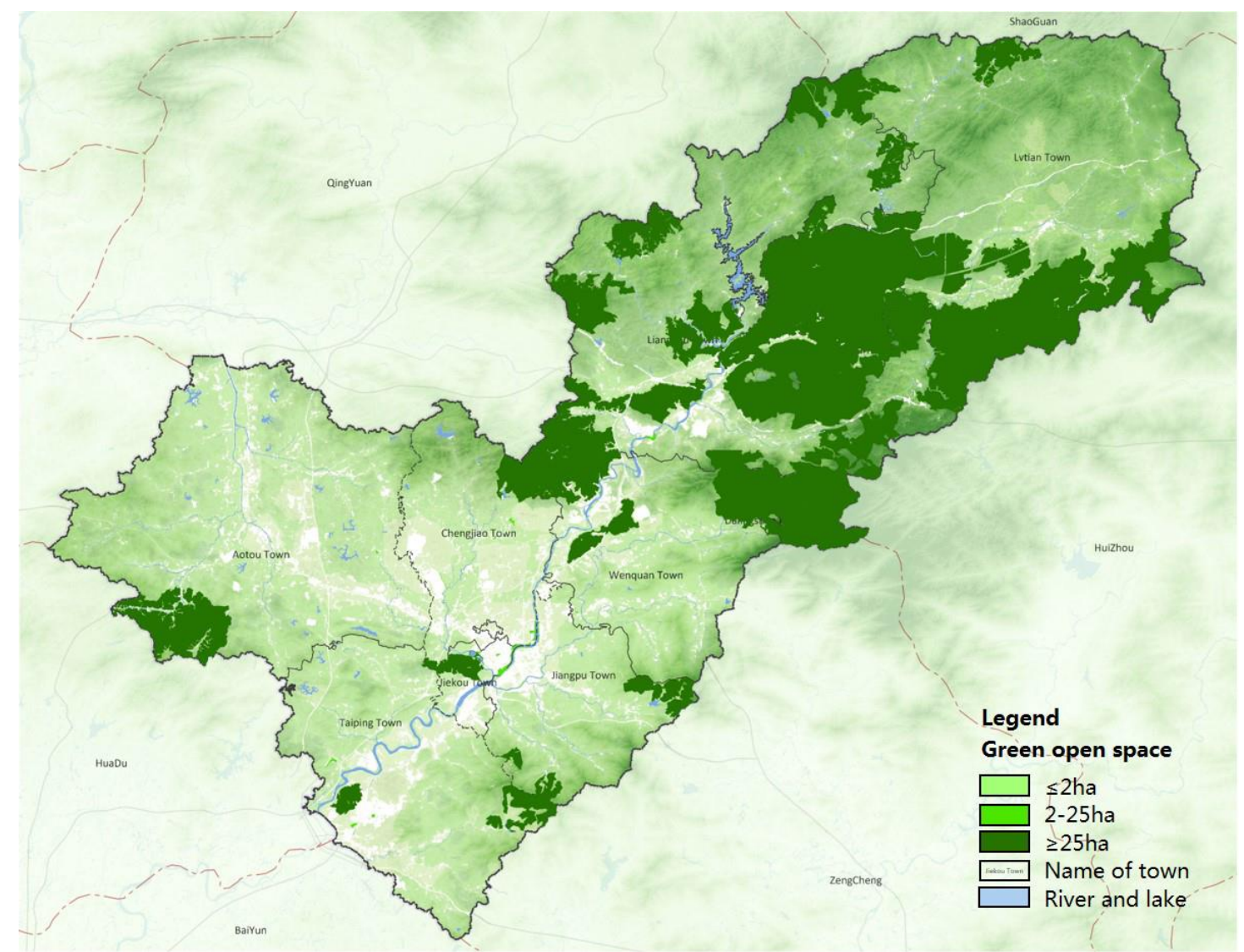

Figure 4 Distribution of green open space in Conghua District. Source: The relevant data of Guangzhou green system and authors' survey.

\section{Characteristics analysis of crowd activities in the green open space}

According to the land area, traffic location, and park type, this paper selects Qingyun Park, Cultural Park and Shimen Forest Park as representatives of urban community parks, suburban ecological parks and outer suburban parks to study the characteristics of crowd activities. Through field observation and recording the number of activities in the park, the frequency of activities of the crowd is analyzed. Through cell phone signaling data analysis and superimposed POI data points, the intensity of crowd activity in different parks is compared. Through field interviews and observations, summarize the characteristics of the types of crowd activities in different parks. Considering the frequency, intensity and type of crowd activities, crowd activities in the green open space of Conghua District show three characteristics as a whole. (1) People in daily leisure activities prefer urban community parks with high convenience for sports activities. (2) The crowds with leisure activities on weekends prefer the suburban ecological park for its high traffic accessibility and open space. (3) The crowds with activities during holidays and vacations prefer the suburban country park for its good environmental quality.

\subsection{Activity Frequency Characteristics}

Combining the recording and on-site interviews, we can conclude that the frequency of crowd activities has a strong correlation with the distribution of green open spaces. The residents interviewed reported that the frequency of activities in urban community parks can usually reach 16-20 times per month (4-5 times per week), while the frequency of activities in suburban ecological spaces is usually 4-8 times per month (1 per week). -2 times), the frequency of activities in outskirts country parks is reduced to $0-1$ times 
a month. During the interview, residents reported that the park's accessibility to traffic was also an important factor influencing the choice of activities.

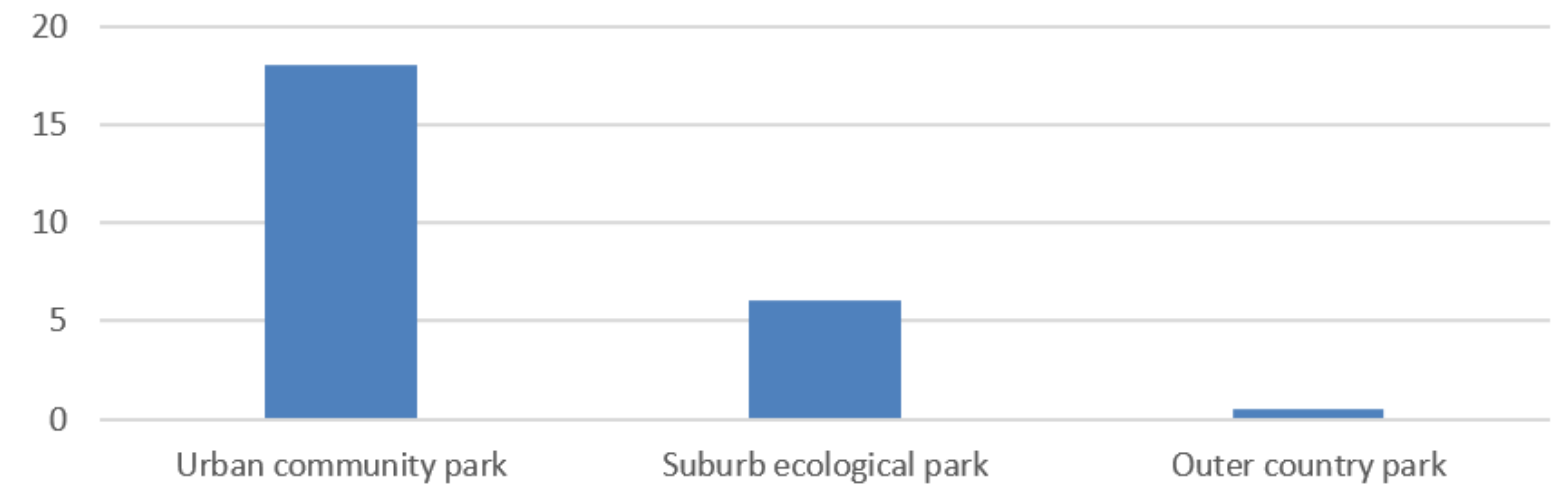

Figure 5 Green open space crowd activity frequency analysis in Conghua District. Source: Authors' survey.

\subsection{Activity Intensity Characteristics}

This article receives mobile phone signaling data in three time periods on September 15, 2020 (data source from the local major communications company) and found that there are certain characteristics of the intensity of crowd activity in different parks. (1) Due to factors such as location and accessibility in urban community parks, the overall crowd activity intensity is relatively high. The highest activity intensity in a day is in the evening, which is consistent with the work pattern of the crowd. (2) In the suburban ecological park, the highest activity intensity in a day is noon. Through field observation, this feature is related to the fact that the activity crowd is mainly tourists. (3) The overall activity intensity of the Suburb Forest Park during working days is low, which is related to its location and traffic accessibility. Generally speaking, people's activities in green open spaces have recovered slightly after the pandemic. This reflects that green open spaces have stronger ecological resilience than the urban built environment. Meanwhile, it also reflects people's growing pursuit of health after the pandemic. The pattern of life activities has become more intense, and green open spaces with better ecological quality fit into people's demands more than urban environments.
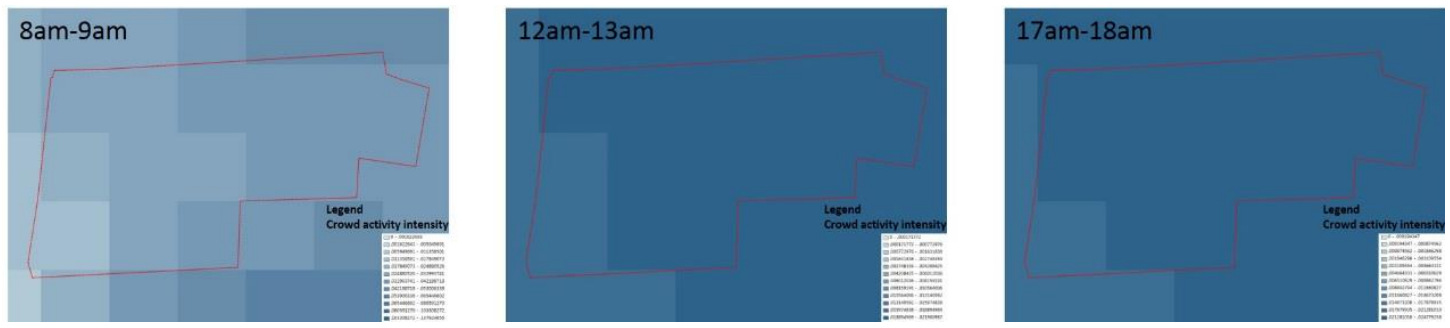

Figure 6 Analysis of crowd activity intensity in Qingyun Park. Source: The local major communications company.
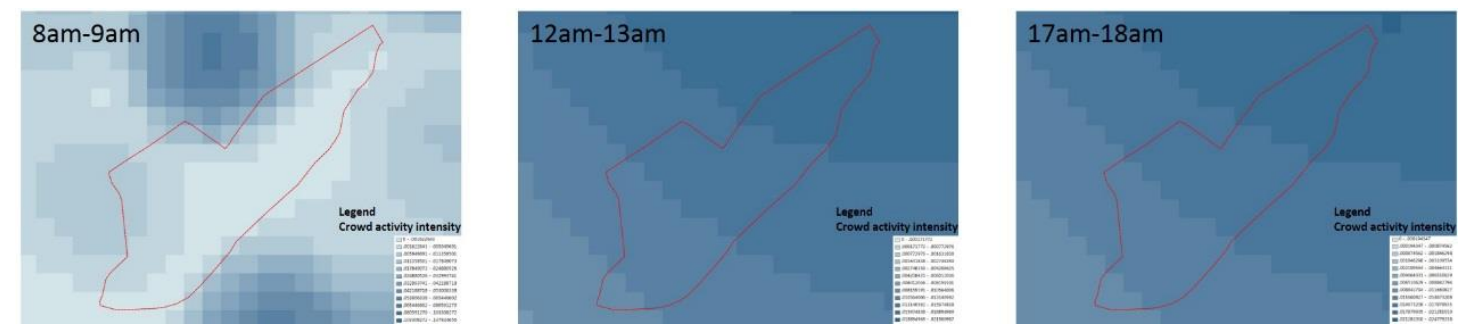

Figure 7 Analysis of crowd activity intensity in Cultural Park. Source: The local major communications company. 

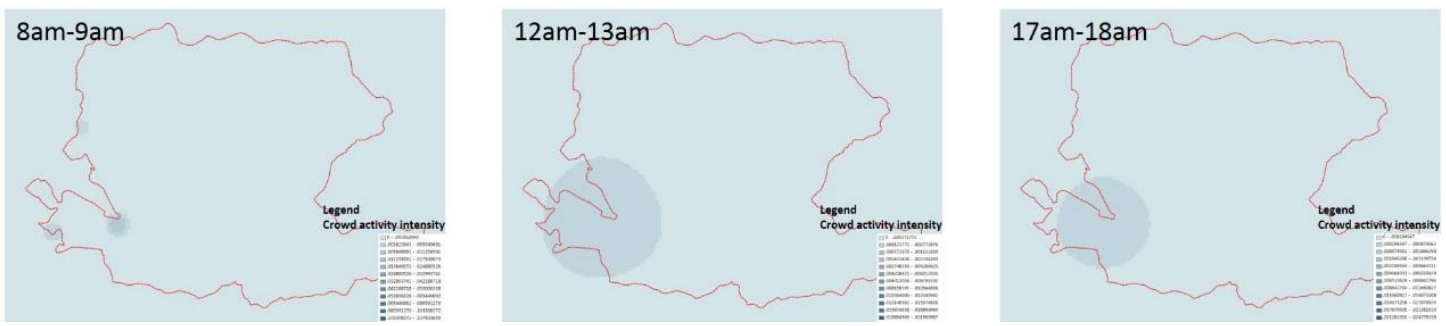

Figure 8 Analysis of crowd activity intensity in Shimen Forest Park. Source: The local major communications company.

According to this assumption, the outer suburbs forest park with the best ecological quality should show stronger crowd activity intensity, however, the actual case is different. Therefore, this article selected green open spaces of similar scale and location (Qingyun Park and Tropic of Cancer Park) and superimposes the POI data around these two parks. The green open space with higher distribution density shows stronger crowd activity intensity. This also shows that when formulating green open space promotion strategies, instead of simply focusing on the quality of the ecological environment, we should improve the overall quality of green open spaces. We found that for crowd activities, although the ecological environment is important to attract people for outdoor activities, the complete supporting infrastructure is a more influencing factor.
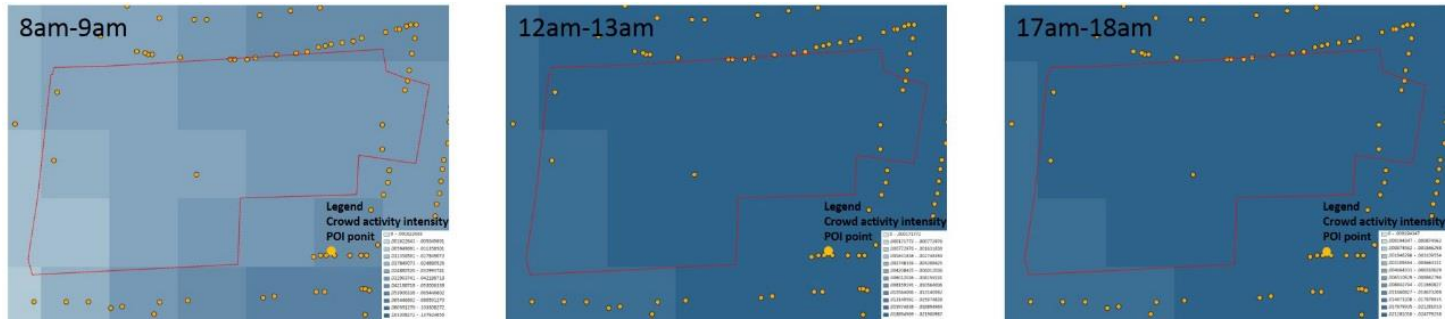

Figure 9 Analysis of croed activity intensity in Qingyuan Park (Superimposing POI point). Source: The local major communications company and authors' survey.
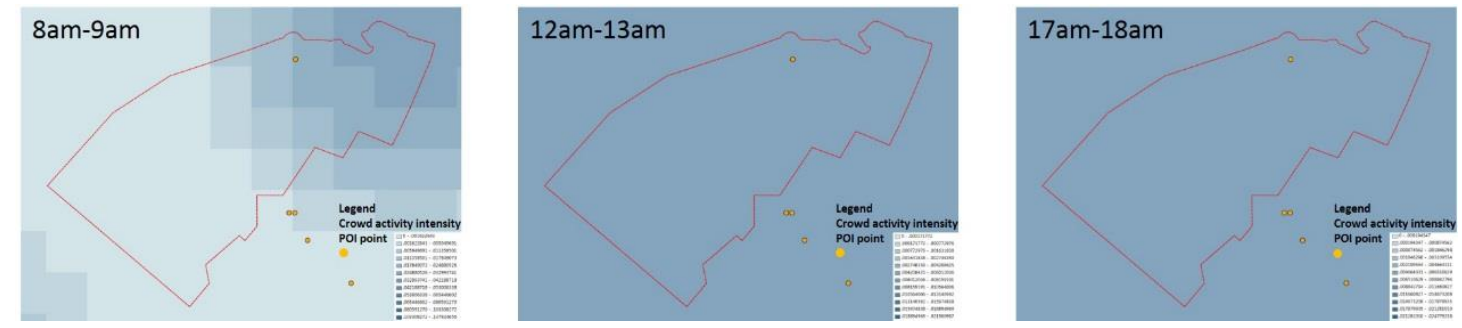

Figure 10 Analysis of crowd activity intensity in the Tropic of Cancer Park (Superimposing POI point). Source: The local major communications company and authors' survey.

\subsection{Activity Type Characteristics}

Through field interviews and observations, this study found that there is a certain correlation between the types of people's activities and the scale of green open space: (1) Daily activities with low-scale requirements, such as walking and jogging, mainly occur in small-scale urban community parks. (2) Influenced by schedules on weekdays and weekends, family leisure activities on weekends mainly take place in suburban ecological parks with high accessibility and open space. (3) Some outdoor activities, such as hiking and climbing, which require larger space and natural environment, as well as less frequency but longer vacation time, mostly take place in national parks with large natural area, for its better environment far away from the urban. 


\section{Linking Strategies between Green Open Space and Healthy Activitiy in Conghua}

\subsection{Promoting the accessibility of green open spaces based on low-impact development}

In addition to meeting the activity needs of the people, the green open space also has an important ecological role in ensuring ecological safety and maintaining biological connectivity. Therefore, we first need to maintain the basic ecological value of the green open space and carry out appropriate development with the concept of low impact. According to the previous analysis of the activity frequency of the crowd in the green open space, we found that the activity frequency between the crowds is mainly affected by the distribution location and traffic accessibility of the green open space. Based on the above factors, this study believes that the construction of green open spaces shouldn't focus on the needs of human activities. It is necessary to transform from the previous human-oriented model to biological-oriented development, and fully study the migration paths of wildlife. Before constructing the space for human activities, it is important to reserve an ecological corridor to ensure the ecological function of the green open space. In addition, it is necessary to improve the accessibility of green open spaces by strengthening the connectivity of public transportation, so that we can expand the scope of crowd activities with much lower carbon emission.

\subsection{Customizing promoting strategies based on the characteristics of crowd activities in different types of parks}

Through the analysis of the superposition of mobile phone signaling and POI data in the previous article, it is known that the recovery speed of street vitality in green open spaces with superior ecological environment quality is faster, and the intensity of crowd activities in the same type of green open spaces with richer functional configurations is stronger. The characteristics have a huge impact on the construction of different green open spaces: (1) As a whole, it is necessary to further improve the environmental quality of the green open space in Conghua District to provide people with a more comfortable and natural place for activities in the post-pandemic era. (2) For urban community parks, due to convenient transportation and superior location, people with limited traffic mobility such as the elderly and children basically play in such green open spaces. Therefore, more child- and elder-friendly facilities need to be added into the fields. (3) For the suburban ecological park, on the one hand, it is an important link between urban and biological environment, where human activities are limited; on the other hand, we should consider that people have the need to get close to the nature. Therefore, the promoting strategy for such type of green open space needs to pay attention to balance the habitat for wildlife while provide people with opportunities to get close to nature in appropriate areas. (4) For suburban and national parks far away from city, it mainly assumes the role of ecological base in the biological environment and has a very critical impact on maintaining balance and sustainability of the ecological environment. Therefore, we advocate to protect the ecological environment in those parks. With the primary principle of "protection first, development supplemented", we may control the number and frequency of human activities in some areas.

\subsection{Enhancing the connectivity of green open spaces provides possibilities for the}

\section{extension of crowd activities}

Different types of crowd activities mainly occur in green open spaces of corresponding scales, but through field research, we found that crowd activities would also extend along with the connection of green open spaces. For example, people jogging along Liuxi Riverside will pass through several small and medium-sized community parks and street green spaces. Normally, they will stop and relax in green open spaces of different scales on the way. People go hiking in Yadonghe Park, and you can enter Shimen Forest Park as 
walking along the river. Invisibly, crowd activities are continuous in green open spaces of different scales. Through remote sensing images and ARCGIS analysis, it can be seen that the total amount of green open space in Conghua District is very large. The biological connectivity of the northern ecological area is better, while such connectivity of the southern area is significantly reduced due to the impact of urban construction. Considering the current status of urban development in Conghua District, it is impossible to increase green open space through large-scale demolition and construction. Therefore, this article proposes the improvement strategy of "greening through cracks" to decrease the gap between green open spaces of different scales, so that we could increase the spatial connectivity and provide the possibility for crowd activities to extend in different green open spaces.

\section{Conclusion and Discussion}

The sudden Covid pandemic has been affecting people's production and life in all aspects. Remote office, online shopping and other modes have been through new developments. Such pandemic has also stimulated people's pursuit of ecological and natural needs for better health. Green open space, as the main material carrier for recreation, sports and other fitness lifestyles, unlocks more diversified values than ever during the post-pandemic era. In the future, the planning of green open space needs to further analysis of the differences in crowd activities in different green open space and propose more effective planning strategies to actively promote the construction of "healthy China".

\section{References}

[1]Zhou, K., Chen, Y.Y., \& Chen, Z. (2021). Health-Oriented Open Green Space Supply in Urban Environment. Journal of Human Settlements in West China. (02),11-22.

[2]Stigsdotter, U. K., Ekholm, O., Schipperijn, J., Toftager, M., Kamper-Jørgensen, F., \& Randrup, T. B. (2010). Health promoting outdoor environments - Associations between green space, and health, health-related quality of life and stress based on a Danish national $\mathrm{n}$ representative survey. Scandinavian Journal of Public Health, 38(4), 411-417.

[3]Cackowski, J. M., \& Nasar, J. L. (2003). The Restorative Effects of Roadside Vegetation: Implications for Automobile Driver Anger and Frustration. Environment and Behavior, 35(6), 736-751.

[4]De Vries, S., Van Dillen S. M. E., Groenewegen, P., \& Spreeuwenberg, P. (2013). Streetscape greenery and health: Stress, social cohesion and physical activity as mediators. Social Science \& Medicine, 33, $0277-$ 9536.

[5]Wang, F. Z. \& Qiu, L. (2015). Recognition Research on the Systematic Function of Green Open in Urban Environment, with an example of Lianyungang Downtown. Geographic Science. (05),583-592.

[6]Liu, T. Y., \& Song, Y. (2015). Evidence-based design and collaboration in healthy urban planning: a case study of the development and implementation of Guidelines for Public Health Space Design in New York City. Planner. (06), 27-33.

[7] Li,D.J \& You,Y.L. (2021). Research on the development strategy of green open space in the mid- and long-term planning of international metropolises and its enlightenment to my country. Construction Technology (12), 14-18+28.

[8] Hu,Y.T., Yu,Y.F. \& Zhang,Q.L.(2021). The impact of green open space on the social interaction of the elderly and its environmental characteristics: Based on the survey of the public housing community in Yangpu District, Shanghai. Shanghai Urban Planning (02), 96 -103. 
[9]Shi, W.Z. (2021). Green space management for high-quality development goals: Taking Sheffield as an example. Urban Architecture (11), 31-34+46.

[10]Z, Y.N. (2020). Preliminary study on the comprehensive land consolidation model of urban and suburban areas under the background of rural revitalization. Small town development (11), 28-33.

[11] Chen, Z. \& Meng, Y. (2020). Public health-oriented urban park landscape experience and recreational behavior research. Landscape Architecture (09), 50-56.

[12]Xu, S. \& He, Z.Y. (2020). Research on the impact of community green open space on neighborhood communication satisfaction. Modern City Research (08), 44-52.

[13]Huang, H.N., Li, D.S. \& Yan, Y.F. (2020). Environmental design research on the impact of urban green open space on the health of people from the perspective of health. Modern Horticulture (13), 135-137.

[14] Chen, Z. \& Zhao, S.R. (2018). Urban green open space planning and design to improve mental health. Urban Architecture (24), 51-56.

[15]Yao, Y.N. \& Li, S.H. (2018). Current research status of urban green space based on public health. Chinese Landscape Architecture (01), 118-124.

[16] Ma, M. \& Cai, Z.Y. (2016). Research on urban green open space from the perspective of health: health utility and design response. Chinese Garden (11), 66-70.

[17]Liu, J.L. (2021). Discussion on the landscape renewal of the green open space in northern Anhui based on locality: Taking the renewal and reconstruction of Mengdie Square in Mengcheng County as an example. Modern Horticulture (14), 61-63.

[18] Li, M.Y.X. (2019). Research and enlightenment of near-natural urban river landscape based on green open space. Industrial Architecture (11), 20-24+19.

[19] Yin, Y.C., Zheng, Z.Y. \& Gao, T.Y. (2020). The development experience and enlightenment of urban green open space under the compact city theory. Architecture and Culture (12), 148-149.

[20] Li, W.Q., Gao, H. \& Guo, H.Z. (2020). Research on the "Elevated" Greenway Design Method from the Perspective of "Urban Double Repair"--Take Tonglu Fuchun Greenway as an example. Huazhong Architecture (09), 68-72 . 